\title{
Comparison between vaginal royal jelly and vaginal estrogen effects on quality of life and vaginal atrophy in postmenopausal women: a clinical trial study
}

\author{
Fatemeh Seyyedi ${ }^{1}$, Mahmoud Rafiean Kopaei ${ }^{2}$, Sepideh Miraj ${ }^{3}$
}

\footnotetext{
${ }^{1}$ Resident of Gynecology, Faculty of Medicine, Shahrekord University of Medical Sciences, Shahrekord, Iran

${ }^{2}$ Ph.D. of Pharmacology, Full professor, Cellular and Molecular Research Center, Shahrekord University of Medical Sciences, Shahrekord, Iran

${ }^{3}$ M.D., Gynecologist, Fellowship of Infertility, Assistant Professor, Faculty of Medicine, Shahrekord University of Medical Sciences, Shahrekord, Iran
}

\section{Type of article: Original}

\begin{abstract}
Objective: This study was conducted to evaluate the therapeutic effects of vaginal royal jelly and vaginal estrogen on quality of life and vaginal atrophy in postmenopausal women.

Methods: This double-blind randomized controlled clinical trial was carried out at gynecology and obstetrics clinics of Hajar Hospital of Shahrekord University of Medi $\neg$ cal Sciences (Iran) from January 2013 to January 2014. The study was conducted on married postmenopausal women between 50 and 65 years old. Of 120 patients, 30 individuals were excluded based on the exclusion criteria, and 90 women were randomly distributed into three groups of 30 royal jelly vaginal cream 15\%, vaginal Premarin, and placebo (lubricant), for three months. At the beginning and the end of the study, quality of life and vaginal cytology assay were evaluated. Data were analyzed by SPSS Version 11.

Results: Vaginal cream of royal jelly is significantly more effective than vaginal cream of Premarin and lubricant in improvement of quality of life in postmenopausal women $(\mathrm{p}<0.05)$. Moreover, Pap smear results showed that vaginal atrophy in vaginal Premarin group was lower than the other groups $(\mathrm{p}<0.001)$, and there was no significant difference between lubricant and royal jelly groups $(\mathrm{p}=0.89)$.

Conclusion: Administration of vaginal royal jelly was effective in quality-of-life improvement of postmenopausal women. Given to the various properties of royal jelly and its effectiveness on quality of life and vaginal atrophy in postmenopausal women, further studies are recommended for using =royal jelly in improving menopausal symptoms.

Clinical trial registration: The trial was registered at the Iranian Registry of Clinical Trials (http://www.irct.ir) with the IRCT code: $2014112220043 n 1$.

Funding: Shahrekord University of Medical Sciences supported this research (project no. 1440).

Keywords: Royal jelly, Conjugated estrogen (Premarin), Vaginal atrophy, Quality of life, Menopause
\end{abstract}

\section{Introduction}

The general health of middle-aged women is a main public health concern worldwide (1). Pre-menopause, or menopause transition, is described by metabolic, neuroendocrine, and behavioral changes associated with enhanced affective disorders (2). Tangen et al. indicated a considerably higher rate of depression and anxiety in the pre- and the post-menopause while comparing premenopausal women (3). The evidence suggested that menopause and depression are interdependent, but a common clear causative factor has not yet been known. Women with climacteric symptoms such as hot flushes, vaginal dryness, night sweats, and dyspareunia are more probable to report symptoms of anxiety and/or depression. Symptoms of vasomotor could be associated with sleep disorders, which, in turn, can enhance symptoms of depression and anxiety. Psychosocial and biological factors have important

\section{Corresponding author:}

Assistant Professor Dr. Sepideh Miraj, Faculty of Medicine, Shahrekord University of Medical Sciences, Shahrekord, Iran.Tel: +98.9126509952, Fax: +98.32225456, Email: miraj.sepide@gmail.com

Received: April 03, 2016, Accepted: September 04, 2016, Published: November 2016 iThenticate screening: September 02, 2016, English editing: September 28, 2016, Quality control: October 16, 2016 (C) 2016 The Authors. This is an open access article under the terms of the Creative Commons Attribution-NonCommercialNoDerivs License, which permits use and distribution in any medium, provided the original work is properly cited, the use is non-commercial and no modifications or adaptations are made. 
effects on middle-aged women with sexuality and affective disorders (4). Pre- and the post-menopause women are not only marked by hormone changes but also frequently accompanied by stressful events and alterations in personal, family, and professional responsibilities. Hormonal changes during the pre- and the post-menopause period could contribute to worsening of healthy lifestyles, quality of life, and general performance of women (4). Vulvovaginal atrophy (VVA) can occur at any age, but it is more frequent in the postmenopausal phase. Symptoms of VVA can unfavourably affect interpersonal relationships, quality of life, and urinary and sexual function (5). First-line therapies of VVA symptoms include non-hormonal treatments such as vaginal lubricants, moisturizers, and regular sexual activity (6). Most lubricants have a temporary effect and should be used immediately before and during sexual activity to reduce tissue irritation and fragility. In contrast, vaginal moisturizers are applied internally at orderly intervals, are longer-acting, and can reduce vaginal dryness and vaginal $\mathrm{pH}$ (7). For women who do not respond to lubricants and moisturizers, estrogen therapy has been suggested as a standard modality of treatment (6). Different types of vaginal estrogen such as conjugated estrogens, estradiol and estradiol vaginal cream, low-dose estradiol and estradiol-release tablets have been applied (8). Regardless of reassessments in recent years, hormone therapy remains controversial, and most postmenopausal women request a natural method such as alternative and complementary therapies to deal with their symptoms (8). Royal jelly (RJ) is known as a complementary therapy. Royal jelly is a special diet for queen honey bees produced by young worker bees. Besides, RJ plays a key role in the growth of honey bee larvae (9). Royal jelly has effective antimicrobial activity and estrogen-like effects. It influences atherosclerosis, diabetic foot ulcers, arthritis, tissue collagen repair, and warts $(10,11)$. The present study aimed to compare the therapeutic effects of vaginal cream of royal jelly and estrogen on quality of life and vaginal atrophy of postmenopausal women.

\section{Material and Methods}

\subsection{Trial design and participants}

This study was a double-blind randomized controlled clinical trial that was conducted on 120 married postmenopausal women referred to Women Clinics of Hajar Hospital in 2014. The women were randomly assigned in this clinical trial, and all of the women signed a consent form. Then, women entered their information on a questionnaire containing demographic characteristics, medical history, and pregnancy information.

\subsection{Selection criteria}

\subsubsection{Inclusion criteria}

Patients with the following conditions were included in the study: not having intercourse during the last 24 hours, lack of vaginal douching in the last 48 hours, refraining from using vaginal cream within the last week, lack of having luggage vaginal within the last 24 hours, not having spotting, age between 50 and 65 years old, at least 12 months of amenorrhea and/or having FSH test more than 40 IU, normal Pap smear within the last 3 years, symptoms of vaginal atrophy, vaginal $\mathrm{pH}>5$, having sexual activity, and naturally menopause women.

\subsubsection{Exclusion criteria}

Exclusion criteria: dissatisfaction to participate in the study, prolapse grade 2 and more of bladder and uterus, surgery of anterior posterior repair (APR), history of sexual problems, chronic or systemic disease (e.g., diabetes, personal and family [first-degree family] history of breast or endometrial cancer, history of endometriosis, personal and family [first-degree family] history of thromboembolism, optic nerve disease, chronic liver disease, migraine, epilepsy and hereditary dyslipidemia), use of hormones, sensitivity to estrogenic compounds, allergy to honey and its products and divorced women, non-normal TVS.

\subsection{Instruments}

The Menopause-Specific Quality of Life (MENQOL) questionnaire includes 29 questions, which measure signs and symptoms of menopause women in four areas of vasomotor (three items), mental-social (seven items), physical (16 questions), and sexual (three questions). Quality of life, vasomotor problems, psychosocial problems, physical problems, and sexual problems were assessed using a quality-of-life questionnaire form, including 29 questions from postmenopausal women. The questionnaire is based on seven-point Likert scale (zero points, i.e., not having symptoms and a score of 6, i.e., having maximum severity of symptoms); with respect to each question, a total score is calculated. Higher scores indicating worse quality of life in each area and the lower the score the better the quality of life. A section related to sexual and urinary problems (five items) was considered and evaluated in the questionnaire to assess sexual function and urinary tract problems. The validity of questionnaire was obtained 0.85 by Cronbach's alpha. This questionnaire has been used in various studies in Iran and is standardized. Ghazanfar Pour and his colleagues in their study reported Cronbach's alpha for the questionnaire as 0.9 , which is an acceptable number (14). The questionnaire was completed by women residents before and at the end of the intervention period 
for each of the subjects by individual interviews. Cytological examination of the cervix and vagina was carried out before and after the study and patients' Pap smear samples were taken at the end of the study.

\subsection{Interventions}

Pap smear samples were taken from qualified women. Thus, with the help of a spatula, the sampling of exocervical and endocervical areas was taken, and it was pulled over onto separate sections of a slide. The slides were fixed immediately with alcohol $96 \%$. The samples were sent to pathology at the end of the day and were interpreted by a pathologist. Finally, 90 women were randomly selected, and then they were divided into three therapeutic groups: placebo (KY Jelly manufacturing ABURAIHAN Pharmaceutical Company), vaginal estrogen $0.625 \mathrm{mg}$ (Premarin manufacturing ABURAIHAN Pharmaceutical Company), and vaginal cream of royal jelly $15 \%$ in lubricant base.The intervention period lasted three months. The way of using the creams were taught to patients at the beginning of the study. Each of the samples in the three study groups were advised to use vaginal cream based on the following schedule: The first and second week: an applicator per night. Third and fourth week: an applicator for every other night. Fifth week until the end of the twelfth week: an applicator, two nights per week.The amounts of phenols, flavonoid, and flavonols of royal jelly measured $12.2 \mathrm{mg} / \mathrm{g}, 45.62 \mathrm{mg} / \mathrm{g}$, and $60.47 \mathrm{mg} / \mathrm{g}$, respectively. Antioxidant activity of royal jelly was determined by DPPH method $15 \%$. In this study, the percentage of observed parabasal cells in Pap smear samples was the criteria of the severity of vaginal atrophy, in a way that increased in the number of parabasal cells and decreased in superficial cells, which indicated more severity of atrophy (49). Because the aim was to determine the effect of three types of cream on the severity of vaginal atrophy and to compare the patient's condition before and after using this cream, a collaborator pathologist, who was unaware of the study groups, classified and reported severe atrophy as follows based on the percentage of parabasal cells in LAM of patients (14). The antioxidant activity of royal jelly was evaluated by DPPH (2, 2-diphenyl-1picrylhydrazyl) assay (15).

\subsection{Outcome}

The primary outcomes of our analyses were the determination of the effect of three types of cream on the severity of vaginal atrophy. Also, the secondary outcomes from the analyses were the comparison of the patient's condition before and after using this cream, comparison of quality of life, sexual symptoms, urinary symptoms, physical health, vasomotor dimension, mental health scores.

\subsection{Sample size}

The sample size was calculated to be 90 subjects. This sample size was calculated based on the results of previous studies (15) by assuming the test power of $80 \%$ and a confidence level of $95 \%$.

\subsection{Randomization and blinding}

Random allocation sequence was allowed to randomly enter menopause women. To conceal allocation, all the tubes were prepared the same and were named A, B, C. Those who entered the study randomly received the creams. Physicians, pathologists, and patients were all unaware of prescribed medications for patients (the study was doubleblind).

\subsection{Statistical methods}

Data summarization methods for continuous data were done by mean and standard deviation, and data summarization methods for categorical data were done by frequency tables; $\mathrm{p}<0.001$ was considered to be significant. Data were analyzed by SPSS version 11 (SPSS Inc., Chicago, Illinois, USA) through the KolmogorovSmirnov test, ANOVA, and Tukey tests.

\subsection{Ethical consideration}

All procedures performed in studies involving human participants were in accordance with the ethical standards of the institutional and/or national research committee and with the 1964 Helsinki Declaration and its later amendments or comparable ethical standards. Informed consent was obtained from all individual participants included in the study. Ethical no. of this research is 92-10-13. The research was approved by the Ethics Committee of Shahrekord University of Medical Sciences.

\section{Results}

In this study, 90 postmenopausal women were divided into three groups consisting of 30 individuals; finally, we had 27 individuals in the lubricant group, 22 in Premarin, and 24 in the royal jelly group (Figure 1). The reason for 
losing some individuals was not to follow-up. The mean age of participants was $53.57 \pm 4.89$ at the age range between 45 and 65 years. The mean age of beginning menopause was $48.33 \pm 4.97$ years at the age range between 45 and 57 years. Body mass index was $28.5 \pm 4.17 \%$ at the age range between 19 and $41 \%$. Regarding to education, most of the participants (54.4\%) were illiterate. The mean of number of delivery in the three groups was $5.21 \pm 2.66$ and $95.8 \%$ and were housewives. Regarding personal characteristics, the participants were the same (Table 1).

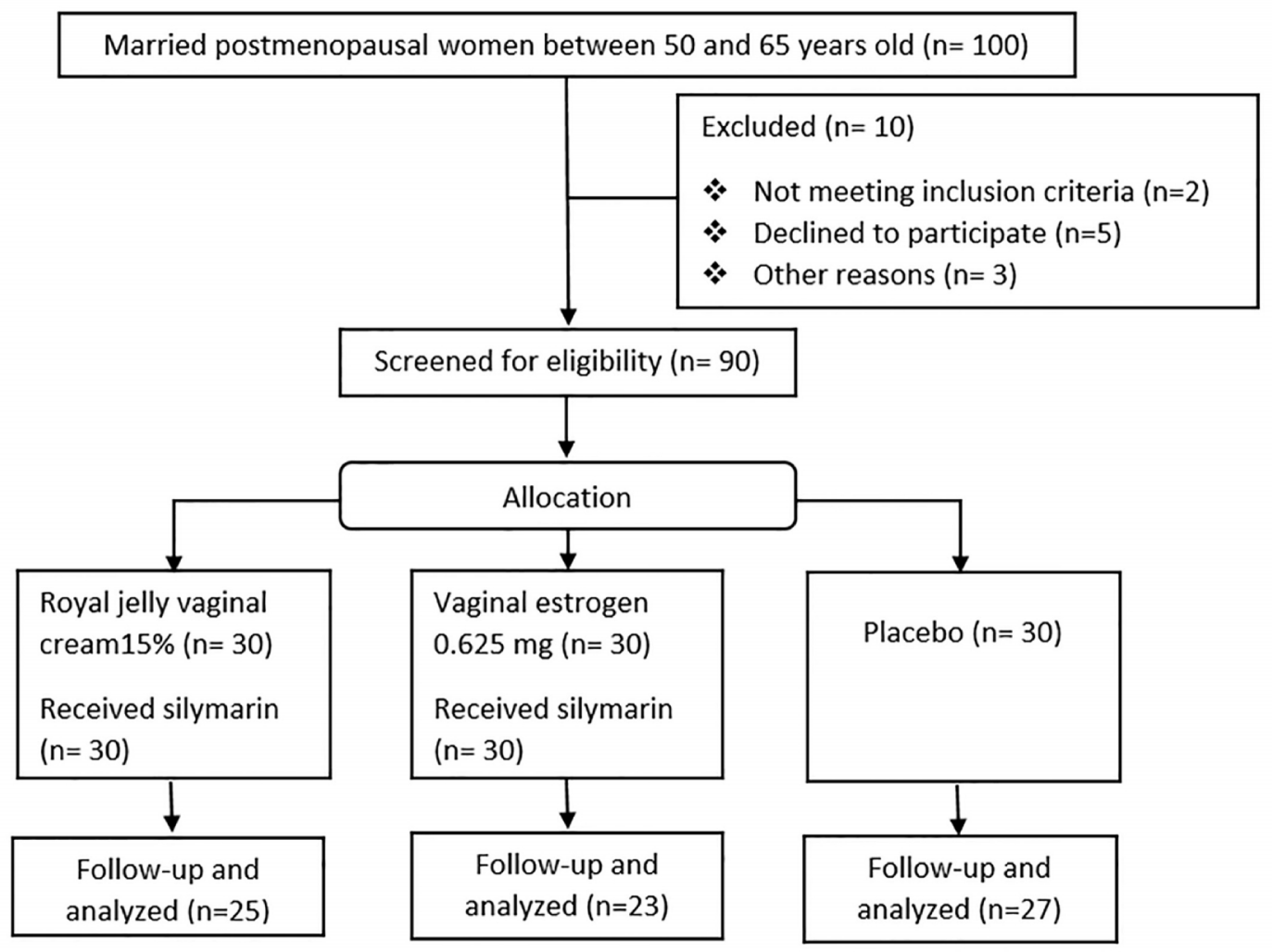

Figure 1. The CONSORT flow diagram of the trial

Table 1. Demographic Characteristics of the Participants ${ }^{\mathrm{a}}$

\begin{tabular}{|c|c|c|c|c|c|}
\hline \multicolumn{2}{|l|}{ Variables } & Lubricant group & Premarin group & Royal jelly group & $p$-value \\
\hline \multicolumn{2}{|l|}{ Age (year) } & $54.37 \pm 4.75$ & $53.72 \pm 5.12$ & $52.79 \pm 4.88$ & 0.52 \\
\hline \multicolumn{2}{|c|}{ Menopause age (year) } & $49.16 \pm 3.81$ & $49.44 \pm 2.52$ & $46.42 \pm 6.98$ & 0.09 \\
\hline \multicolumn{2}{|c|}{ Body mass index $\left(\mathrm{kg} / \mathrm{m}^{2}\right)$} & $29.43 \pm 3.95$ & $26.97 \pm 4.16$ & $28.98 \pm 4.17$ & 0.10 \\
\hline \multicolumn{2}{|l|}{ Number of delivery } & $5.92 \pm 2.49$ & $5.04 \pm 2.47$ & $4.66 \pm 2.92$ & 0.23 \\
\hline \multirow[t]{2}{*}{ Employment status } & Housekeeper & 26 & 20 & 21 & 0.14 \\
\hline & Employee & 4 & 10 & 9 & \\
\hline \multirow[t]{5}{*}{ Education } & Illiterate & 13 & 11 & 13 & \multirow[t]{5}{*}{0.34} \\
\hline & Elementary & 8 & 4 & 3 & \\
\hline & Secondary school & 3 & 2 & 1 & \\
\hline & High school and diploma & 1 & 1 & 4 & \\
\hline & College & 3 & 1 & 3 & \\
\hline
\end{tabular}

${ }^{a}$ Data are presented as Mean \pm SD.

In addition, at the beginning of the study, the severity of vaginal atrophy and the mean of quality of life of women in the three groups were similar; therefore, the groups were matched (Table 2). The results suggested a significant difference between three groups at the end of intervention regarding to aspects of quality of life, sexual-urinary problems and vaginal cytology (vaginal atrophy) $(\mathrm{p}<0.05)$. Besides, it was indicated that vaginal royal jelly and Premarin were more effective than vaginal lubricant in improving the quality of life in postmenopausal women $(p<0.05)$. Effectiveness of royal jelly in improving the quality of life was more than Premarin $(p>0.001)$. The results 
http://www.ephysician.ir

of Pap smear showed that the group of Premarin had the most reduction in the parabasal cells of the vagina and improvement of vaginal atrophy. In addition, significant differences between the groups receiving lubricant and Premarin were shown $(\mathrm{p}=0.004)$. The group received Premarin had lower parabasal cells $(\mathrm{p}=0.004)$. However, no significant difference was observed comparing royal jelly group with the lubricant group field ( $\mathrm{p}=0.89$ ). Furthermore, significant differences were observed between the groups receiving royal jelly and Premarin ( $p=0.02$ ), and vaginal atrophy in patients using Premarin was less than the royal jelly group (Table 3 ).

Table 2. Comparison of Quality of Life and Severity of Vaginal Atrophy in the Three Groups, at the Beginning of the Study ${ }^{\mathrm{a}}$

\begin{tabular}{|l|l|l|l|l|}
\hline Variables & Lubricant group & Premarin group & Royal jelly group & $p$-value \\
\hline Vasomotor problems & $8.88 \pm 5.45$ & $8.45 \pm 5.08$ & $10.37 \pm 5.60$ & 0.44 \\
\hline Psychosocial problems & $14.03 \pm 8.64$ & $17.54 \pm 8.79$ & $18.54 \pm 9.90$ & 0.18 \\
\hline Physical problems & $41.77 \pm 18.54$ & $41.31 \pm 14.84$ & $50.41 \pm 17.52$ & 0.12 \\
\hline Sexual problems & $11.37 \pm 5.85$ & $12.00 \pm 5.30$ & $12.91 \pm 5.83$ & 0.62 \\
\hline Quality of life & $76.07 \pm 29.20$ & $79.31 \pm 26.24$ & $92.25 \pm 30.56$ & 0.12 \\
\hline Vaginal atrophy & $2.26 \pm 1.25$ & $2.27 \pm 1.31$ & $2.12 \pm 1.19$ & 0.89 \\
\hline
\end{tabular}

${ }^{a}$ Data are presented as Mean $\pm \mathrm{SD}$.

Table 3. Comparison of Changes in Quality of Life and Vaginal Atrophy in Groups ${ }^{\text {a }}$

\begin{tabular}{|l|l|l|l|l|}
\hline Variables & lubricant group & Premarin group & Royal jelly group & $p$-value \\
\hline Vaginal atrophy & $-0.38 \pm 0.63$ & $-0.51 \pm 0.67$ & $-1.23 \pm 1.26$ & 0.004 \\
\hline Sexual function* & $-0.81 \pm 3.06$ & $-4.83 \pm 4.17$ & $-4.45 \pm 2.93$ & $<0.001$ \\
\hline Mental health** & $-0.07 \pm 1.77$ & $-6.27 \pm 4.23$ & $-7.95 \pm 7.36$ & $<0.001$ \\
\hline Physical problems*** & $-2.11 \pm 6.11$ & $-14.31 \pm 8.04$ & $-16.95 \pm 11.04$ & $<0.001$ \\
\hline Vasomotor problems**** & $-0.33 \pm 1.51$ & $-5.31 \pm 4.15$ & $-5.54 \pm 3.90$ & $<0.001$ \\
\hline Quality of life***** & $-.3 .18 \pm 9.37$ & $-35.29 \pm 20.29$ & $-30.36 \pm 14.39$ & $<0.001$ \\
\hline
\end{tabular}

a Data are presented as Mean \pm SD.

Table 4. Covariates of Comparison of Changes in Quality of Life, Sexual Symptoms, Urinary Symptoms, Physical Health, Vasomotor Dimension, Mental Health Scores in the Group Studied

\begin{tabular}{|c|c|c|c|}
\hline Covariates of comparisons & Group & Mean \pm SD & $p$-value \\
\hline \multirow[t]{3}{*}{ comparison of changes in quality of life scores } & Lubricant & $9.37 \pm 3.18$ & \multirow[t]{3}{*}{$<0.001$} \\
\hline & Premarin & $14.39 \pm 30.36$ & \\
\hline & Royal & $35.29 \pm 20.29$ & \\
\hline \multirow[t]{3}{*}{ Comparison of changes in scores of sexual symptoms } & Lubricant & $93.2 \pm 45.4$ & \multirow[t]{3}{*}{$<0.001$} \\
\hline & Premarin & $17.4 \pm 83.4$ & \\
\hline & Royal & $16.5 \pm 79.3$ & \\
\hline \multirow[t]{3}{*}{ Comparison of changes in urinary symptoms } & Lubricant & $4.2 \pm 0.59$ & \multirow[t]{3}{*}{$<0.001$} \\
\hline & Premarin & $57.2 \pm 50.2$ & \\
\hline & Royal & $68.3 \pm 95.3$ & \\
\hline \multirow[t]{3}{*}{ Comparison of changes in physical health } & Lubricant & $2.11 \pm 6.11$ & \multirow[t]{3}{*}{$<0.001$} \\
\hline & Premarin & $4.8 \pm 31.14$ & \\
\hline & Royal & $4.11 \pm 95.16$ & \\
\hline \multirow[t]{3}{*}{ Comparison of changes in vasomotor dimension } & Lubricant & $0.33 \pm 1.51$ & \multirow[t]{3}{*}{$<0.001$} \\
\hline & Premarin & $15.4 \pm 31.5$ & \\
\hline & Royal & $90.3 \pm 54.5$ & \\
\hline \multirow[t]{3}{*}{ Comparison of changes in mental health } & Lubricant & $0.07 \pm 1.77$ & \multirow[t]{3}{*}{$<0.001$} \\
\hline & Premarin & $6.27 \pm 4.23$ & \\
\hline & Royal & $7.95 \pm 7.36$ & \\
\hline \multirow[t]{3}{*}{ Comparison of changes in Pap smear } & Lubricant & $0.63 \pm 0.38$ & \multirow[t]{3}{*}{$<0.001$} \\
\hline & Premarin & $1.32 \pm 1.26$ & \\
\hline & Royal & $0.15 \pm 0.67$ & \\
\hline
\end{tabular}


Regarding sexual function, there was a significant difference between groups using a lubricant and Premarin $(p=0.001)$. Besides, there was significant difference between groups using a lubricant and royal jelly $(p<.001)$, and no significant difference between groups taking Premarin and royal jelly was observed ( $\mathrm{p}=0.92)$. Regarding mental health, there was a significant difference between groups using a lubricant and Premarin $(\mathrm{p}<0.001)$. In addition, significant difference between groups using a lubricant and royal jelly $(\mathrm{p}<0.001)$ was observed. There was no significant difference between groups using Premarin and royal jelly $(\mathrm{p}=0.46)$. Regarding to physical problems, there was a significant difference between groups using a lubricant and Premarin $(\mathrm{p}<0.001)$, and there was a significant difference between groups using a lubricant and royal jelly $(\mathrm{p}<0.001)$ but there was no significant difference between groups using Premarin and royal jelly $(\mathrm{p}=0.53)$. Regarding to vasomotor problems, there was a significant difference between groups using a lubricant and Premarin $(\mathrm{p}<0.001)$, and there was a significant difference between groups using a lubricant and royal jelly $(\mathrm{p}<0.001)$ but no significant difference was observed between groups taking Premarin and royal jelly $(\mathrm{p}=0.97)$. Regarding quality of life, there was a significant difference between groups using lubricant and Premarin $(\mathrm{p}=0.01)$ and significant difference between groups taking lubricant and royal jelly was observed $(\mathrm{p}=0.002)$, but no significant difference was observed between groups taking Premarin and royal jelly $(\mathrm{p}=0.55)$ (Table 4). Evaluation of antioxidant and royal jelly compounds showed that the amount of phenol flavonoid and flavanol were $12.12,45.62,60.47$, respectively, and the antioxidant activity of the gel was $15 \%$.

\section{Discussion}

Findings of the study showed that vaginal cream of royal jelly is significantly more effective than vaginal cream of Premarin and lubricant in improvement of quality of life in postmenopausal women. In addition, Premarin was more effective than the lubricant in improving various aspects of quality of life. The rate of vaginal atrophy in the group receiving Premarin was significantly reduced compared with the other two groups. The etiology of sexual disorders in postmenopausal women is often multifactorial and may contain psychological disorders such as depression or anxiety, conflict in interpersonal relationship, tiredness, stress, medications, prior physical or sexual abuse, and physical disorders that make sexual activity painful such as endometriosis or atrophic vaginitis (16). Vulvovaginal disorders had a negative impact on social and sexual life in postmenopausal women (17) and can decrease one's self-esteem (18). Besides, given that levels of testosterone naturally decline in postmenopausal women, low testosterone levels may involve to the decrease in arousal and sexual response (19). In a study, approximately 56\% of postmenopausal women represented dyspareunia secondary to vaginal dryness (20). The dyspareunia can be a factor in reducing libido (21). Thus, positive effects of royal jelly and Premarin on quality of life in postmenopausal women participating in the study are probably due to their therapeutic effects on sexual and urinary problems through their estrogenic properties. Moreover, Pap smear results at the end of the study showed that vaginal atrophy in the Premarin group was lower than in the other groups, and there is no significant difference between groups of royal jelly and lubricant. Royal jelly is traditionally used to recover from menopausal problems. The potential estrogenic properties of RJ were examined using diverse approaches. RJ competes for connection of 17 betaestradiol to the human estrogen receptor alpha and beta but acts weaker than phytoestrogens and diethylstilbestrol. Studies related to gene expression showed that $0.1-1 \mathrm{mg} / \mathrm{ml}$ RJ activates estrogen receptors. Studies reported evidence that RJ has estrogenic activities via interaction with estrogen receptors after endogenous gene expressions (22). Therefore, therapeutic effects of royal jelly in this study can be justified due to estrogenic properties and stimulating estrogen receptors. RJ stimulates making collagen and other activities for bone construction via action on osteoblasts. This role is one of the useful therapeutic attributes of royal jelly in menopause (23). Further, royal jelly is known as being part of a useful diet containing many helpful minerals. Nakaya et al. found that royal jelly has an anti-environmental estrogen property. Bisphenol $\mathrm{A}$ is an environmental estrogen that increases proliferation of MCF-7 cells in human breast cancer. Royal jelly inhibits the stimulatory effect of growth of Bisphenol A on MCF-7 cells $(24,25)$. It has been proposed that RJ may have an antioxidant function, and studies found that RJ supplementation considerably enhanced glutathione peroxidase activities and erythrocyte superoxide dismutase and considerably decreased Malondialdehyde levels $(15,26)$. RJ comprises $60 \%-70 \%$ water, $12 \%-15 \%$ proteins, $10 \%-$ $12 \%$ carbohydrates, 3\%-7\% lipids, $1.5 \%$ mineral salts and various vitamins. RJ has anti-inflammatory and antibacterial functions (15). Studies have discovered the functions of the estrogen receptors, progesterone receptors, and p53 in stress urinary incontinence (SUI) and pelvic organ prolapse (POP) (27). Urinary incontinence may cause women to restrict their activities and limit their social interactions (28). During menopause, vaginal atrophy and alterations in vaginal $\mathrm{pH}$ can cause problems such as itching, irritation, and higher risk of vaginal infections (29). Antimicrobial and anti-inflammatory effects of royal jelly can be helpful in improving disorders. In addition, royal jelly is made up of $60 \%-70 \%$ percent water. Water increases the moisture inside the vagina and reduces vaginal 
dryness, though temporarily. Therefore, the multiple functions of royal jelly enable improvement of symptoms of postmenopausal women and enhance their quality of life. Local estrogen is highly efficient in relieving symptoms of urogenital atrophy and enhanced libido and in improving sexual function in symptomatic postmenopausal women. Testosterone also increases energy, sense of well-being, libido, and sexual performance (30). The results of a study by Long et al. suggested that estrogen therapy alone enhances the vaginal blood stream and improves some sexual activities in postmenopausal women with hysterectomy surgery of compared with systemic therapy, and topical vaginal compounds were shown to associate with enhanced symptom relief (31). Raymundo et al. showed that vaginal treatment with vaginal cream of conjugated equine estrogens resulted in favorable changes in vaginal tissues (32). Besides, topical vaginal estrogen compounds reverse atrophic alterations, relieve the symptoms, and prevent systemic effects (33). In Raghunandan et al.'s study, the effects of local estrogen with or without local testosterone on sexual and urogenital health in postmenopausal women were investigated. Some women received local estrogen cream; others received local estrogen and testosterone cream; and the control group received no hormonal lubricant. They found that local estrogen, either alone or with androgen, is greatly effective in recovery of urogenital atrophy symptoms and sexual function in symptomatic postmenopausal women without any side effects (30). Urinary incontinence is frequently associated with negative effects on quality of life of patients. Severity of disease, physical image of oneself and one's response to problems are among the factors affecting the quality of life. Also, vulvovaginal atrophy is associated with urinary symptoms such as dysuria, nocturia, frequency, recurrent urinary tract infections, and incontinence (34). In this study, treatment with royal jelly and Premarin improved psychological status in postmenopausal women. This is in line with the results of Koundi and colleagues. The authors concluded in their study that hormone therapy upgrades the quality of life and psychological health in postmenopausal women (35). Studies have shown that sexual hormones, particularly estrogen, can affect mental health, including cognitive development and function, mood, and vulnerability to neurodegenerative disorders and brain injury. Morita et al. also showed that royal jelly improves quality of life and psychological health of the participants in their study (36). This is in line with the results of Seyyedi et al. that vaginal royal jelly was effective in improving symptoms of sexual and urinary problems and quality of life in postmenopausal women (37).

\section{Limitations of study}

In this study, vaginal royal jelly had problems such as low formidability and antioxidant effects and women were in trouble when using it. Probably low formidability and concentration of royal jelly in the vaginal environment caused low therapeutic effects on vaginal atrophy and vaginal cytology. Therefore, by providingmore appropriate compound with higher concentration of royal jelly, the possibility of greater effectiveness of this compound may be provided in subsequent studies.

\section{Conclusions}

In this study, administration of vaginal royal jelly was effective in improving symptoms of vaginal atrophy and quality of life in postmenopausal women. Given to the various properties of royal jelly and its effectiveness on quality of life and vaginal atrophy in postmenopausal women, further studies are recommended for using of royal jelly in improving menopausal symptoms.

\section{Acknowledgments:}

This study was part of a medical thesis and was supported by a grant of Shahrekord University of Medical Sciences, Research Council, Shahrekord, Iran. The authors thank all those who helped us in this study.

\section{Clinical trial registration:}

The trial was registered at the Iranian Registry of Clinical Trials (http://www.irct.ir) with the IRCD code: $2014112220043 n 1$.

\section{Funding:}

Shahrekord University of Medical Sciences supported this research (project no. 1440).

\section{Conflict of Interest:}

There is no conflict of interest to be declared.

\section{Authors' contributions:}

All authors contributed to this project and article equally. All authors read and approved the final manuscript. 


\section{References:}

1) G KP, Arounassalame B. The quality of life during and after menopause among rural women. J Clin Diagn Res. 2013; 7(1): 135-9. doi: 10.7860/JCDR/2012/4910.2688. PMID: 23450244, PMCID: PMC3576769.

2) Reis FM, Pestana-Oliveira N, Leite CM, Lima FB, Brandão ML, Graeff FG, et al. Hormonal changes and increased anxiety-like behavior in a perimenopause-animal model induced by 4-vinylcyclohexene diepoxide (VCD) in female rats. Psychoneuroendocrinology. 2014; 49: 130-40. doi: 10.1016/j.psyneuen.2014.06.019. PMID: 25080405.

3) Tangen T, Mykletun A. Depression and anxiety through the climacteric period: an epidemiological study (HUNT-II). J Psychosom Obstet Gynaecol. 2008; 29(2): 125-31. doi: 10.1080/01674820701733945. PMID: 18484441.

4) Llaneza P, Garcia-Portilla MP, Llaneza-Suarez D, Armott B, Perez-Lopez FR. Depressive disorders and the menopause transition. Maturitas. 2012; 71(2): 120-30. doi: 10.1016/j.maturitas.2011.11.017. PMID: 22196311.

5) Nappi RE, Palacios S. Impact of vulvovaginal atrophy on sexual health and quality of life at postmenopause. Climacteric. 2014; 17(1): 3-9. doi: 10.3109/13697137.2013.871696. PMID: 24423885.

6) Management of symptomatic vulvovaginal atrophy: 2013 position statement of The North American Menopause Society. Menopause. 2013; 20(9): 888-902. doi: 10.1097/GME.0b013e3182a122c2. PMID: 23985562.

7) Suckling J, Lethaby A, Kennedy R. Local oestrogen for vaginal atrophy in postmenopausal women. Cochrane Database Syst Rev. 2006(4): CD001500. doi: 10.1002/14651858.CD001500.pub2. PMID: 17054136.

8) Pitkin J. Alternative and complementary therapies for the menopause. Menopause int. 2012; 18(1): 20-7. doi: 10.1258/mi.2012.012001. PMID: 22393177.

9) Ishii R, Horie M, Murayama M, Maitani T. [Analysis of tetracyclines in honey and Royal jelly by LC/MS/MS]. Shokuhin Eiseigaku Zasshi. 2006; 47(6): 277-83. PMID: 17228793.

10) Abdelatif M, Yakoot M, Etmaan M. Safety and efficacy of a new honey ointment on diabetic foot ulcers: a prospective pilot study. J Wound Care. 2008; 17(3): 108-10. doi: 10.12968/jowc.2008.17.3.28667. PMID: 18376651.

11) Melliou E, Chinou I. Chemistry and bioactivity of Royal jelly from Greece. J Agric Food Chem. 2005; 53(23): 8987-92. doi: 10.1021/jf051550p. PMID: 16277392.

12) Ghazanfarpour M, Kaviani M, Rezaiee M, Ghaderi E, Zandvakili F. Cross cultural adaptation of the menopause specific questionnaire into the persian language. Ann Med Health Sci Res. 2014; 4(3): $325-9$. doi: 10.4103/2141-9248.133453. PMID: 24971202, PMCID: PMC4071727.

13) Bachmann GA, Nevadunsky NS. Diagnosis and treatment of atrophic vaginitis. American family physician. 2000; 61(10): 3090-6.

14) Pourmoradian S, Mahdavi R, Mobasseri M, Faramarzi E, Mobasseri M. Effects of Royal jelly supplementation on glycemic control and oxidative stress factors in type 2 diabetic female: a randomized clinical trial. Chin J Integr Med. 2014; 20(5): 347-52. doi: 10.1007/s11655-014-1804-8. PMID: 24610413.

15) Avis NE, Brockwell S, Randolph JF Jr, Shen S, Cain VS, Ory M, et al. Longitudinal changes in sexual functioning as women transition through menopause: results from the Study of Women's Health Across the Nation. Menopause. 2009; 16(3): 442-52. doi: 10.1097/gme.0b013e3181948dd0. PMID: 19212271, PMCID: PMC2908487.

16) Mishima S, Suzuki KM, Isohama Y, Kuratsu N, Araki Y, Inoue M, et al. Royal jelly has estrogenic effects in vitro and in vivo. J Ethnopharmacol. 2005; 101(1-3): 215-20. doi: 10.1016/j.jep.2005.04.012. PMID: 15946813.

17) Narita Y, Nomura J, Ohta S, Inoh Y, Suzuki KM, Araki Y, et al. Royal jelly stimulates bone formation: physiologic and nutrigenomic studies with mice and cell lines. Biosci Biotechnol Biochem. 2006; 70(10): 2508-14. doi: 10.1271/bbb.60240. PMID: 17031045.

18) Okic-Djordjevic I, Trivanovic D, Krstic J, Jaukovic A, Mojsilovic S, Santibanez JF, et al. GE132+Natural: Novel promising dietetic supplement with antiproliferative influence on prostate, colon, and breast cancer cells. J BUON. 2013; 18(2): 504-10. PMID: 23818369.

19) Cumming GP, Herald J, Moncur R, Currie H, Lee AJ. Women's attitudes to hormone replacement therapy, alternative therapy and sexual health: a web-based survey. Menopause Int. 2007; 13(2): 79-83. PMID: 17540139. 
20) Cumming GP, Currie HD, Moncur R, Lee AJ. Web-based survey on the effect of menopause on women's libido in a computer-literate population. Menopause Int. 2009; 15(1): 8-12. doi: 10.1258/mi.2009.009001. PMID: 19237616.

21) Mishima S, Suzuki KM, Isohama Y, Kuratsu N, Araki Y, Inoue M, et al. Royal jelly has estrogenic effects in vitro and in vivo. J Ethnopharmacol. 2005; 101(1-3): 215-20. doi: 10.1016/j.jep.2005.04.012. PMID: 15946813.

22) Narita Y, Nomura J, Ohta S, Inoh Y, Suzuki KM, Araki Y, et al. Royal jelly stimulates bone formation: physiologic and nutrigenomic studies with mice and cell lines. Biosci Biotechnol Biochem. 2006; 70(10): 2508-14. doi: 10.1271/bbb.60240. PMID: 17031045.

23) Okic-Djordjevic I, Trivanovic D, Krstic J, Jaukovic A, Mojsilovic S, Santibanez JF, et al. GE132+Natural: Novel promising dietetic supplement with antiproliferative influence on prostate, colon, and breast cancer cells. J BUON. 2013; 18(2): 504-10. doi: 10.1016/j.jep.2005.04.012. PMID: 23818369.

24) Nakaya M, Onda H, Sasaki K, Yukiyoshi A, Tachibana H, Yamada K. Effect of Royal jelly on bisphenol A-induced proliferation of human breast cancer cells. Biosci Biotechnol Biochem. 2007; 71(1): 253-5. doi: 10.1271/bbb.60453. PMID: 17213647.

25) Cavusoglu K, Yapar K, Yalcin E. Royal jelly (honey bee) is a potential antioxidant against cadmiuminduced genotoxicity and oxidative stress in albino mice. J Med Food. 2009; 12(6): 1286-92. doi: 10.1089/jmf.2008.0203. PMID: 20041783.

26) Sharife N, Hasanzadeh MM, Ayate S, Shakeri M, Goroneh Z. Evaluation of expression estrogen receptor and progesterone receptor and p53 in patients with stress urinary incontinence and pelvic organ prolapse. JBUMS. 2012; 14(1(64)): 25-30.

27) Koc AN, Silici S, Kasap F, Hormet-Oz HT, Mavus-Buldu H, Ercal BD. Antifungal activity of the honeybee products against Candida spp. and Trichosporon spp. J Med Food. 2011; 14(1-2): 128-34. doi: 10.1089/jmf.2009.0296. PMID: 21128826.

28) Raghunandan C, Agrawal S, Dubey P, Choudhury M, Jain A. A comparative study of the effects of local estrogen with or without local testosterone on vulvovaginal and sexual dysfunction in postmenopausal women. J Sex Med. 2010; 7(3): 1284-90. doi: 10.1111/j.1743-6109.2009.01667.x. PMID: 20102444.

29) Long CY, Liu CM, Hsu SC, Wu CH, Wang CL, Tsai EM. A randomized comparative study of the effects of oral and topical estrogen therapy on the vaginal vascularization and sexual function in hysterectomized postmenopausal women. Menopause. 2006; 13(5): 737-43. doi: 10.1097/01.gme.0000227401.98933.0b. PMID: 16946685.

30) Raymundo N, Yu-cheng B, Zi-yan H, Lai CH, Leung K, Subramaniam R, et al. Treatment of atrophic vaginitis with topical conjugated equine estrogens in postmenopausal Asian women. Climacteric. 2004; 7(3): 312-8. PMID: 15669556.

31) Al-Baghdadi O, Ewies AA. Topical estrogen therapy in the management of postmenopausal vaginal atrophy: an up-to-date overview. Climacteric. 2009; 12(2): 91-105. doi: 10.1080/13697130802585576. PMID: 19117185.

32) Ko Y, Lin SJ, Salmon JW, Bron MS. The impact of urinary incontinence on quality of life of the elderly. Am J Manag Care. 2005; 11(4 Suppl): S103-11. PMID: 16161383.

33) Coyne KS, Sexton CC, Irwin DE, Kopp ZS, Kelleher CJ, Milsom I. The impact of overactive bladder, incontinence and other lower urinary tract symptoms on quality of life, work productivity, sexuality and emotional well-being in men and women: results from the EPIC study. BJU Int. 2008; 101(11): 1388-95. doi: 10.1111/j.1464-410X.2008.07601.x. PMID: 18454794.

34) Koundi KL, Christodoulakos GE, Lambrinoudaki IV, Zervas IM, Spyropoulou A, Fexi P, et al. Quality of life and psychological symptoms in Greek postmenopausal women: association with hormone therapy. Gynecol Endocrinol. 2006; 22(12): 660-8. doi: 10.1080/09513590601010557. PMID: 17162707.

35) Morita H, Ikeda T, Kajita K, Fujioka K, Mori I, Okada H, et al. Effect of Royal jelly ingestion for six months on healthy volunteers. Nutr J. 2012; 11: 77. doi: 10.1186/1475-2891-11-77.

36) Seyyedi F, Rafiean M, Miraj S. Comparison of the Effects of Vaginal Royal Jelly and Vaginal Estrogen on Quality of Life, Sexual and Urinary Function in Postmenopausal Women. J Clin Diag Res. 2016; 10(5). doi: $10.7860 / j \mathrm{cdr} / 2016 / 17844.7715$. 